\title{
DELITOS DE FEMICIDIO Y FEMINICIDIO EN PAÍSES DE AMÉRICA LATINA
}

RESUMEN: Un acercamiento político-conceptual a los procesos de tipificación penal de las muertes violentas de mujeres en catorce países de América Latina, constituye el propósito de este texto. Entre 2007 y 2015, con el liderazgo de activistas, juristas, investigadoras, madres, hermanas e hijas de mujeres asesinadas y con aportes de los debates feministas y de género se han incorporado dos tipos penales: el femicidio y el feminicidio. La primera figura ha sido adoptada en Costa Rica, Guatemala, Chile, Nicaragua, Honduras, Panamá, Ecuador y República Bolivariana de Venezuela, haciendo énfasis en estudios realizados por investigadoras empeñadas en develar las condiciones estructurales de las muertes violentas. La segunda figura tiene un lugar propio en las normas de El Salvador, México, Perú, Estado Plurinacional de Bolivia, Brasil y Colombia, implementando sistemas de registro que continúan siendo frágiles. En su configuración han sido determinantes tanto las condiciones estructurales como la cercanía entre atacantes y atacadas para orientar el sentido de la investigación penal.

Palavras clave: Tipos penales emergentes. Procesos de tipificación. Femicidio y feminicidio. Violencias de género. Feminismo punitivo.
ABSTRACT: A political-conceptual approach to the processes of criminalization of violent deaths of women in fourteen countries of Latin America, is the purpose of this text. Between 2007 and 2015, with the leadership of activists, jurists, researchers, mothers, sisters and daughters of murdered women and with contributions from feminist and gender debates, two criminal types have been incorporated: femicide and feminicide. The first figure has been adopted in Costa Rica, Guatemala, Chile, Nicaragua, Honduras, Panama, Ecuador and the Bolivarian Republic of Venezuela, emphasizing studies conducted by researchers engaged in unveiling the structural conditions of violent deaths. The second figure has its own place in the norms of El Salvador, Mexico, Peru, the Plurinational State of Bolivia, Brazil and Colombia, implementing registration systems that continue to be fragile. In its configuration have been determining both the structural conditions and the proximity between attackers and attacked to guide the meaning of criminal investigation.

Keywords: Emerging criminal types. Typing processes. Femicide and femicide. Gender violence. Punitive feminism.

\footnotetext{
${ }^{1}$ Profesora titular con tenencia de cargo de la Universidad Nacional de Colombia, adscrita al Departamento de Comunicación Humana, vinculada a la Escuela de Estudios de Género, e investigadora del I.D.H.: Instituto de Desarrollo humano, (Dis) Capacidades, Diversidades.. Posdoctora en Estudios de género; Doctora en Teoría sociológica: comunicación, conocimiento y cultura; Magistra en Sociología de la Educación; Abogada Penalista; Fonoaudióloga.
} 


\section{APERTURA PARA SITUAR EL TEMA}

El texto expone un acercamiento a los procesos de tipificación penal de las muertes violentas de mujeres que fueron realizados en catorce países de América Latina, durante el periodo 2007-2015, y a los dos tipos penales incorporados en los códigos existentes o en legislaciones específicas. Con el trabajo mancomunado de activistas, juristas, investigadoras, madres, hermanas e hijas de mujeres asesinadas y con el cobijo de los debates feministas y de género, las propuestas penales también han servido para sopesar la ausencia de la debida diligencia a cargo del aparato estatal para garantizarles a las mujeres una vida libre de violencias.

Las muertes violentas de mujeres en distintos países de América Latina han sido analizadas por estudiosas deseosas de denunciarlas e interesadas en hacerlas visibles a través de la penalización. Las proponentes han recurrido a diversas estrategias teóricas o empíricas que les ha permitido nombrar a estos hechos violentos con palabras del lenguaje común, los han delimitado con términos específicos y los han conceptualizado hasta configurar una tipificación género-sensitiva. El delito de femicidio ha sido adoptado en ocho países: Costa Rica, Guatemala, Chile, Nicaragua, Honduras, Panamá, Ecuador y República Bolivariana de Venezuela; y el delito de feminicidio en seis: El Salvador, México, Perú, Estado Plurinacional de Bolivia, Brasil y Colombia. Con sus descripciones se pueden comprender, investigar y sancionar las circunstancias que rodean las muertes y las violencias vividas por ciertos grupos de mujeres que no son meras víctimas.

\section{CONTEXTO POLÍTICO-CONCEPTUAL}

La tipificación de los delitos de femicidio y feminicidio que han sido adoptados en 14 países latinoamericanos entre 2007 y 2015, se basan en una estrategia político-conceptual esgrimida desde posturas feministas con la intención de visibilizar las muertes violentas por razones de género, pero también hacen parte de los compromisos estatales para cumplir con las previsiones de la Convención sobre la Eliminación de Todas las Formas de 
Discriminación contra la Mujer $\left(\right.$ Cedaw $\left.^{2}\right)$ y de la Convención Interamericana para Prevenir, Sancionar y Erradicar la Violencia contra la Mujer (Belém do Pará). La denuncia, la documentación, la investigación y la sanción penal para quienes resulten responsables de los hechos criminales, han surgido de la lucha colectiva y del activismo orientado a defender una vida libre de violencias para las mujeres; por eso, en palabras de Adriana Ramos, es indispensable disponer de "una perspectiva relacional de los derechos, vinculada a una resignificación del concepto de autonomía, que tenga en cuenta los vínculos, las relaciones sociales, y el contexto" $(2015, \text { p. } 17)^{3}$.

Sabiendo que los hechos punibles también se resignifican según las circunstancias vividas y el sentido pragmático dado a las palabras según lo planteado por Gadamer, como se cita en Elvia María González (2011, p. 138), es decir que "los conceptos que yo empleo en mi contexto quedan redefinidos por su uso", en este artículo se habla de dos tipos penales incorporados a la legislación en países de la región latinoamericana. Con estas alternativas punitivas, pero sin olvidar los límites de los debates punitivos generados, que aún no concluyen, estamos ante un asunto político-conceptual orientado a problematizar las estructuras sociales a través de tres verbos muy presentes en las reflexiones, las acciones y los debates feministas: nombrar ${ }^{4}$, visibilizar ${ }^{5}$ y conceptualizar ${ }^{6}$.

\footnotetext{
${ }^{2}$ Sigla en inglés.

${ }^{3}$ Siguiendo a Marcela Lagarde (2017, p. 369), “los derechos humanos sintetizados en la última década del siglo son la columna vertebral de las mujeres: el derecho a la vida en primera persona, el derecho al desarrollo personal y a los beneficios del desarrollo, el derecho a la democracia con equidad para arribar a la igualdad, el derecho a la protección y a la seguridad por parte del Estado, el derecho al trato respetuoso y a la integridad personal. el derecho a la justicia plena, el derecho a vivir una vida sin miedo y sin violencia, el derecho a la paz social y a la paz en la vida cotidiana".

${ }^{4}$ La acción de nombrar ha sido una constante en la lucha política como también en la vida cotidiana de las mujeres, que pronto se tomaría los espacios académicos, las investigaciones, las calles, las expresiones artísticas y las cortes, procurando la concientización de lo que le sucede más comúnmente a ciertos grupos de mujeres y a ciertos colectivos por su identidad de género.

${ }^{5}$ La acción de visibilizar y hacer visible las violencias se han convertido en la base de la transformación social emprendida por las activistas que optaron por el camino de la denuncia; esta acción no se desliga de las reflexiones hechas por Érika Lindig, cuando advierte que "el término "visibilidad", referido al ámbito de lo político, puede tener distintos sentidos [...] "visibilidad macropolítica", entendiendo lo macropolítico como el "ejercicio de política soberana y representativa que, fundándose en la identidad del individuo o de la nación, produce y reproduce aquello de lo que dice originarse [...]. Una segunda manera de entender el término "visibilidad" tendría que ver [...] con el discurso de resistencia de las víctimas y sus familiares que producen nuevas formas de la colectividad y de la experiencia, [que] llamaremos "visibilidad micropolítica" (p. 348).

${ }^{6}$ La acción de conceptualizar, en su sentido de postura política, ha servido a las mujeres para politizar sus reclamaciones y para dar sentido a los efectos de la ideología imperante con el fin de develar las bases de la configuración del delito de femicidio/feminicidio.
} 
Con el verbo nombrar, la muerte violenta ${ }^{7}$ de una mujer es mucho más que el tecnicismo de un hecho punible, es la destrucción de su cuerpo y la sustracción de su vida, cuyo reconocimiento deja analizar los sustratos ideológicos ya naturalizados en el seno de la familia, la comunidad, el medio laboral, el ámbito educativo, el sistema judicial, el sector salud o el Estado, e invita a definir los alcances de las distintas formas de opresión vividas por las mujeres en el mundo social. Con el verbo visibilizar, esta muerte violenta queda asociada a un término específico que sigue siendo objeto de debates ${ }^{8} y$, por su intermedio, a un bien jurídico protegido penalmente recogiendo así la movilización de las activistas, intensificando la denuncia de la impunidad estatal y reclamando la garantía de los derechos humanos de las mujeres. Con el verbo conceptualizar, además de tener en mente los nexos de la muerte violenta y sistemática de mujeres con la perspectiva de género, se comprende por qué, según Adriana Ramos, optar por el uso "entre los términos feminicidio y femicidio tiene consecuencias concretas, que no deben ser subestimadas" (2015, p. 19).

Conjugando conscientemente los tres verbos no solo ha sido posible conocer las circunstancias que originan, rodean y silencian la muerte violenta de ciertas mujeres en ciertos lugares y con ciertos nexos estructurales, como lo han analizado Julia Monárrez, Ana Carcedo, Monserrat Sagot, Olga Amparo Sánchez, Patsilí Toledo o Rita Segato. El trabajo de estas investigadoras y analistas, que ha buscado los trasfondos ideológicos de las muertes, ha sido impulsado por familiares de mujeres asesinadas (principalmente madres y hermanas) y por defensoras de los derechos de las mujeres; ambos grupos se han empeñado en develar los cimientos de unas muertes ocurridas en medio de la indolencia social, tal como han sido documentadas poco a poco en México, Guatemala, Perú o Costa Rica, y que dejan unas huellas en los cuerpos mutilados, amputados o

\footnotetext{
${ }^{7}$ Según Elvia María González "algunas palabras se van alejando de su sentido cotidiano y se va especializando su uso en el campo de lenguaje científico, surgen entonces, los términos" (2011, p. 136).

${ }^{8}$ La misma autora, Elvia María González, añade que el término "es una palabra cuyo significado está delimitado unívocamente en cuanto se refiere a un concepto definido. [...] El término, en la medida que es incorporado al diálogo científico, se designa como concepto, algo que se concibe, que se representa intelectualmente, que se aleja de su cotidianidad" (2011, p. 137).
} 
cercenados $^{9}$. La muerte de las mujeres no es un asunto personal ni ocurre en los límites privados de la convivencia de las parejas o de la dinámica de las familias; es un asunto estructural vinculado a una organización sociocultural misógina que se limita a publicar unas cifras incompletas, por eso mismo, reafirmamos con Érika Lindig que:

[...], el trabajo de resistencia de las madres tiene otro efecto: el de crear nuevas formas de participación política. En sus propias prácticas de organización, discusión y denuncia, ellas logran, aunque sea en pequeña escala, cuestionar y modificar los espacios y tiempos que el sistema les ha asignado, y ocupar otros. [...] Incluso nosotras hemos rechazado la cuestión de las cifras porque a muchas de las madres, cuando van a hacer una gestión referente al caso de sus hijas, lo primero que les preguntan es el número de expediente, pero, para ellas, sus hijas no son un número, tenían un nombre, una historia (2017, p. 355, 355, nota 5).

Los tipos penales derivados de los estudios remiten a la palabra inglesa femicide ya que las conductas delictivas se han nombrado y se han hecho visibles a través de los conceptos de femicidio y feminicidio ${ }^{10}$. Este mecanismo punitivo "fue pensado por sus creadoras como una categoría política" (MUJICA; TUESTA, 2012, p. 174) después de haber develado cómo operan las relaciones de género asimétricas, cómo se reproducen las desigualdades sociales y cómo los estereotipos sexuales, raciales y étnicos atraviesan la vida cotidiana de las mujeres. Constituye la reacción socio-política desde los feminismos ante unas violencias y muertes violentas que son resultado de relaciones de poder, dominación y privilegio detentadas por ciertos hombres pero naturalizadas por toda la sociedad, con el aval del silencio legal y por la ausencia de acciones gubernamentales inmediatas para mantener la seguridad ciudadana y defender la vida de la diversidad de mujeres.

Los conceptos que nombran y visibilizan la muerte violenta de las mujeres en términos de femicidios y feminicidios, que han sido elaborados, compartidos o debatidos por analistas sociales, académicas y activistas en trabajos sistemáticos y que han entrado a

\footnotetext{
${ }^{9}$ En casos de muertes violentas, se ha identificado el overkill, "un término utilizado para definir patrones donde se inflige un número excesivo de lesiones que sobrepasan las necesarias para causar la muerte [...]. También se utiliza en circunstancias en las que se presentan dos o más traumas, ya sean cortopunzantes, cortantes, por proyectil de arma de fuego o por golpes severos" (Vergel, et. al, 2013, p. 21).

${ }^{10}$ En el concepto, [...] un lenguaje artificial que siempre necesitará el lenguaje cotidiano para ser comprendido e interpretado por otros, [...] se autodespliegan muchas posibilidades, y desde allí, [...] podrá aportar a la redefinición [y se] puede "intentar siempre efectuar una fluidificación de todas las ofertas lingüísticas" (Gadamer, 2002, p. 19), como se cita en Elvia María González (2011, p. 138).
} 
hacer parte de la vida política, cultural y jurídica de cada país, se basan en observaciones minuciosas de la realidad cotidiana, están reclamando otra clase de lecturas descentradas de las estadísticas criminales oficiales y están hablando en voz alta de las omisiones judiciales. Además, han encontrado que las categorías para medir las violencias con el fin de convertirlas en números pierden sus relaciones con las dinámicas de la organización social y cultural; así, la experiencia de violencia, la trayectoria de las relaciones asimétricas, los significados culturales del género y sus implicaciones en la vida cotidiana, el matrimonio, el parentesco y la sexualidad, no hacen parte de la medición; el contexto social de las violencias, la naturalización de la violencia basada en el género o la inacción y la responsabilidad del Estado, tampoco están en los registros, pues, como lo ha señalado Érika Lindig:

Cuando se habla de "300 asesinatos" se abstraen las condiciones específicas de cada uno de ellos y se oculta la singularidad de cada una de las víctimas: su historia particular. Por ello las madres que rinden testimonio de la desaparición y el asesinato de sus hijas se niegan a hablar de cifras y comienzan por dar sus nombres y los de aquellas por quienes hablan [...]. Además, porque las cifras no te describen el dolor, la impotencia de las familias, el desánimo, no te describen el sufrimiento (2017, p. 351, nota 5).

Por lo pronto, las cifras oficiales ${ }^{11}$ y los subregistros quedan interrogados, sobre todo si tenemos en cuenta, con Carla Gisele Batista, que en el caso de Brasil se ha escrito que durante "el período de 2005 a 2015 se produjo un aumento del 22\% de mujeres de raza negra asesinadas, acompañado de una reducción del 7,4\% de mortalidad de mujeres de raza no negra" (2017, p. 18). En otras palabras, tras estas cifras comunicadas oficialmente se han instalado unos anclajes estructurales que es preciso conocer a fondo porque según las reflexiones de Jennie Dador: "la violencia contra las mujeres no es solo un problema de criminalidad o de inseguridad ciudadana que se vaya a resolver con la penalización de conductas y la restricción de derechos de las potenciales víctimas" (2012,

\footnotetext{
${ }^{11}$ De un lado, los números ofrecen una forma conmensurable de evaluar problemas, obligan a los gobiernos a actuar, crean asuntos de debate público e incrementan la acción, a la vez, oscurecen y olvidan importantes dimensiones de la vida social y de la experiencia colectiva. De otro lado, la violencia estructural, la violencia estatal y las actitudes sociales que toleran o exculpan las violencias, junto a la impunidad estatal y al impacto de las actitudes de la gente hacia las violencias, no son objeto de medición.
} 
p. 20). En realidad, si bien demanda la tipificación también exige transformaciones socioculturales y decisiones políticas con bases estructurales.

\section{A PROPÓSITO DE LA TIPIFICACIÓN PENAL}

Los debates promovidos por mujeres y hombres conscientes de las desigualdades producidas y reproducidas socialmente han abordado distintas posturas en torno a la tipificación especial para juzgar a quienes han incurrido en un delito al causar la muerte violenta de una mujer por ser mujer. El proceso de penalización de estos hechos, además de conceptualizar y hacer visible un fenómeno criminal como parte de unas acciones estatales, que siguen siendo ajenas a las transformaciones estructurales, ponen de presente "que en la legislación penal no existe un tipo penal capaz de recoger todo el desvalor de resultado que la conducta supone" (BENAVIDES, 2015, p. 85).

Los anclajes estructurales. La tipificación penal surge a partir de las violencias vividas por las mujeres pero, también, por la ausencia de la debida diligencia de los Estados ante el incremento "inexplicable y coincidente" de muertes en diferentes regiones. Esta urgencia, según Rita Segato, implica "mostrar la dimensión política de todos los asesinatos de mujeres que resultan de ese control y capacidad punitiva, sin excepción" (2006, p. 3), sobre todo porque si en el cuerpo de cada mujer asesinada se hallan las múltiples huellas del silencio estatal, es preciso reconocer que se requiere de "un tipo penal que también crece en complejidad, por cuanto exige comprobar motivaciones en la conducta del victimario" (TUESTA; MUJICA, 2015, p. 85).

El debate acerca de la tipificación constituye un centro de discrepancias entre quienes han liderado propuestas género-específicas ${ }^{12}$, quienes critican a los feminismos punitivos $^{13}$, quienes se apartan de las iniciativas penales ${ }^{14}$, quienes defienden el

\footnotetext{
${ }^{12}$ Sobre todo al definir el bien o los bienes jurídicos afectados con conductas que provocan daños en el cuerpo pero afectan la libertad, la sexualidad y la vida de las mujeres.

${ }^{13}$ Estefanía Vela Barba y Lucía Núñez proponen un seminario titulado Críticas al feminismo punitivo, que se organiza en torno a una reflexión política, estratégica: ¿Por qué elegir el derecho penal como una herramienta para hacer efectivos estos derechos? ¿Cuáles son sus supuestas ventajas? ¿Qué se gana al tipificar nuevos delitos? ¿Qué se gana enfocando los recursos simbólicos, económicos y humanos en el aparato punitivo? ¿Cuáles son los costos de utilizar esta herramienta? ¿Sirve para los propósitos deseados? ¿Sirve en el contexto mexicano? Para más detalles se puede consultar sitio el web: http://17edu.org/criticas-al-feminismopunitivo/?utm source=newsletter 380\&utm medium=email\&utm campaign=certificado-en-teoria-critica
} 
formalismo jurídico ${ }^{15}$ o quienes buscan medidas objetivas para analizar las huellas encarnadas de las violencias ${ }^{16}$. En medio de estos debates es preciso tener en cuenta los recorridos registrados para acordar qué tipo penal incorporar a la legislación nacional:

[...] es a partir del año 2000 cuando aparecen los primeros estudios que sitúan el foco en México y hacen visibles los asesinatos en Ciudad Juárez. [Julia] Monárrez (2000; 2002; 2009) aborda decididamente este problema a partir del la traducción de Marcela Lagarde del marco planteado por [Jill] Radford y [Diana] Rusell (1992) y [Diana] Rusell (2006) en el que el feminicidio se entiende como una consecuencia de la inequidad y de las relaciones de poder entre hombres y mujeres que justifica y consiente el abuso de los cuerpos de las niñas y de las mujeres, y su asesinato (Boira, et al., 2015, p. 33).

En todo caso hay un acuerdo estratégico: son hechos que demandan la incorporación de los principios y de los alcances del derecho penal para prevenir su ocurrencia en la cotidianidad, investigarlos cuando suceden, enjuiciar a quienes sean responsables e imponerles las penas correspondientes a sus actos mediante sentencias $\operatorname{condenatorias}^{17}$. De ahí que las proponentes de los tipos penales autónomos hayan integrado diferentes circunstancias como elementos del delito e ingredientes subjetivos para diferenciarlos de la figura del homicidio e investigar unas muertes ocurridas por el hecho de ser mujer o que están asociadas a lo femenino o a motivos de identidad de género. Así, cuando se emprenda la investigación es preciso tener en cuenta las estructuras sociales dominantes y las asimetrías de poder en los contextos jerárquicos ya

\footnotetext{
${ }^{14}$ Expresan que se trata de alternativas centradas en el derecho penal de autor, la punición sexualizada, la expansión sancionatoria, la sexualización de las penas, el populismo penal o el giro punitivo y que desvirtúan los principios de igualdad, culpabilidad y tipicidad tan caros a la doctrina penal, la lógica y la filosofía del derecho. Hacen énfasis en las ideas de victimización y esencialismo contenidas en el tipo penal cuando se aducen motivaciones vinculadas al hecho de ser mujer.

${ }^{15}$ El principio de igualdad se desconoce porque la descripción del tipo penal autónomo supone la asignación de mayor valor a la vida de las mujeres. El principio de culpabilidad se desconoce porque se supone que el sujeto activo es un hombre y ser hombre se convierte en una presunción. El principio de tipicidad remite a la indeterminación o la imprecisión de los elementos del delito, estos han de seguir una descripción de estricto orden o tecnicismo penal.

${ }^{16}$ Por ejemplo el "uso del término overkill, cuando existan evidencias de ensañamiento contra el cuerpo de la víctima o se combinen varias acciones violentas como muestra de la idea de propiedad de la mujer asociada a la deshumanización" (Corporación Humanas, 2015, p. 26).

${ }^{17}$ El Equipo Latinoamericano de Justicia y Género -ELA-, como miembro de la Articulación Regional Feminista por los Derechos Humanos y la Justicia de Género, coordina el Observatorio de Sentencias Judiciales, que se propone contribuir al empoderamiento de las mujeres de los países participantes mediante la promoción de una mayor conciencia de los derechos de las mujeres y los medios legales para hacer efectivos estos derechos.
} 
conocidos, sin descuidar el análisis de la debida diligencia por parte de los Estados ${ }^{18}$ para garantizar a las mujeres el disfrute de una vida libre de violencias con medidas directas, expeditas y sin discriminaciones.

La particular cercanía. Aunque las muertes violentas de mujeres ocurren en cualquier contexto, espacio o lugar, los atacantes también pueden ser miembros de la familia de la mujer asesinada, integrantes de su comunidad o compañeros del mundo laboral. Para ello, se han recogido estudios previos sobre las violencias contra las mujeres y estudios que narran los antecedentes de un tipo legal específico. Según Rita Segato, existen unas dimensiones personales e impersonales de los asesinatos, un eje de comunicación vertical entre víctima y perpetrador y otro horizontal entre perpetrador y sus pares. Sabine Maier los describe de la siguiente manera: "en el eje vertical, se manifiestan los principios de control sobre la víctima y la acción dirigida a conservar y reproducir el poder patriarcal, mientras en el eje horizontal, la subordinación de la víctima sirve como requisito para mantener la relación horizontal con los cofrades" $(2015$, p. 68).

Los análisis centrados en los ataques indican que prevalecen, pero no son las únicas, las condiciones de cercanía, parentesco o afinidad de quien ataca, incluso abarca a “cualquier otra relación afectiva” (GONZÁLEZ, 2015, p. 199, nota 32); por eso Teresa Peramato (2012) denuncia que en muchos casos de mujeres asesinadas había una relación entre agresor y agredida que podía ser de matrimonio o de afectividad, con o sin convivencia previa o actual, intermitente o permanente. Aunque los atacantes suelen ser los maridos o cónyuges, los amantes, novios, parejas ${ }^{19}$, $\operatorname{concubinos}^{20}$ o $\operatorname{convivientes}^{21}$, también pueden ser sujetos que han hecho parte de la vida no tan recientemente de la

\footnotetext{
${ }^{18}$ La debida diligencia es una obligación estatal que implica prevenir, proteger, investigar, sancionar y reparar todo acto de violencia. Su manifestación más inmediata consiste en firmar y ratificar las disposiciones de la CEDAW o de Belem do Pará.

${ }^{19}$ Según Mujica y Tuesta (2014, p. 188), ante la existencia de un "problema de registro criminológico del fenómeno "feminicidio" y del registro de los indicadores criminalísticos" se acude a la noción de pareja como uno de los "elementos de registro concreto y de relativo acceso para construir una medición del fenómeno".

${ }^{20}$ Bolivia reconoció el concubinato en su Código de familia de 1977; Brasil hizo lo propio en su nuevo Código civil de 2002; y en el Perú, el Código civil las define en su artículo 326. [...]; el Código de familia costarricense regula latamente el concubinato a partir del Título VII, mientras el Código civil guatemalteco se hace cargo de él en los artículos 173 y siguientes (GONZÁLEZ, 2015, p. 205, nota 47).

${ }^{21}$ Según el Diccionario de la Real Academia Española, conviviente es "cada una de las personas con quienes comúnmente se vive" (GONZÁLEZ, 2015, p. 203, nota 40).
} 
mujer y que llegan a actuar en su condición de ex-maridos o ex cónyuges, ex-amantes, exnovios, ex-parejas, ex-concubinos o ex-convivientes ${ }^{22}$. En otras palabras, la ruptura unilateral decidida por las mujeres implicadas, sin importar cuál haya sido el motivo de su decisión, es la base social de su condena a muerte.

Por eso mismo, conviene no perder de vista que pocas veces se presta atención a cómo los hombres atacantes que matan a quienes consideran sus mujeres, están amparados en la organización sociocultural de la vida cotidiana. Como consecuencia, se ha observado que durante los procesos penales suele haber referencias moralistas a lo que Jennie Dador describe como "discursos amatorios que [en realidad] se sustentan en relaciones de control, disciplinamiento, colonización y posesión sobre el cuerpo y la vida de las mujeres" (2012, p. 20).

Sin duda, si se tiene en cuenta la forma como las conductas de los atacantes "corresponden a un delito cometido en el ámbito de una familia o ex-familia" (CORN, 2015, p. 197), pero también en otros ámbitos y contra ciertos grupos de mujeres, se comprenden los alcances de las violencias y de las muertes violentas como una expresión extrema de las relaciones de dominación o del ejercicio de un control social del que las mujeres no han podido escapar porque, según Jennie Dador, aún falta "un sistema judicial sensibilizado y preparado desde la perspectiva de género que privilegie la protección oportuna y la sanción y reparación efectivas" $(2012, \text { p. } 20)^{23}$.

Las labores de investigación penal. La muerte violenta de las mujeres como forma de violencia extrema por razones de género puede ser entendida en términos de una violencia ejercida por los hombres hacia las mujeres con el propósito de obtener o de mantener el poder, el dominio o el control sobre sus vidas, sus cuerpos y sus acciones. Los actos desencadenantes de las muertes y los cuerpos de las mujeres asesinadas hablan del

\footnotetext{
${ }^{22}$ Cabe pensar en las reflexiones de Jennie Dador y Jeannette Llaja: "la descripción del tipo penal de parricidio, excluye a las ex cónyuges y ex convivientes, así como a los enamorados o ex enamorados, amantes y ex amantes; lo que constituye una limitante para la debida protección del derecho humano a la vida y a una vida libre de violencia; ya que en aras del principio de legalidad, pilar del derecho penal garantista, los operadores del derecho están obligados a juzgar este tipo de casos como homicidio simple" (2008, p. 21).

${ }^{23}$ Según Jennie Dador y Jeannette Llaja, en el expediente y en las actuaciones se "encuentra su mayor expresión en el silencio y en la indiferencia de algunos operadores de justicia quienes no logran sentencias justas, procesos jurídicos transparentes y respetuosos hacia las personas sino, más bien, fomentan con la discriminación, el sentimiento de desprotección y despojo" (2008, p. 62).
} 
menosprecio o de la discriminación relacionada con la condición de la mujer; de los motivos arraigados en el género y de la discriminación manifiesta por motivos de la identidad de género. La intención de matar a una mujer por su condición de tal en el ámbito de las relaciones entre hombres y mujeres, está escrita en sus cuerpos con las cicatrices de las lesiones previas que no solamente han ocurrido en el ámbito restringido de las relaciones con una pareja o con una ex-pareja.

En concordancia con estas afirmaciones, las investigaciones detalladas de cada muerte y el impulso de unos procesos judiciales rigurosos se basan en los aportes feministas y de género, sin olvidar la atención oportuna y específica en salud, la organización de servicios sociales que estén acompañados de campañas socioculturales para cambio de imaginarios, eliminación de estereotipos y sesgos de género. Además, si el propósito es romper con la impunidad, es urgente transformar los sistemas elaborados para registrar todos los casos de violencia de tal manera que integre las cifras ampliadas pero desagregadas y que se adopte una:

[...] legislación específica para la penalización [...], conforme a los estándares internacionales de derechos humanos. Legislaciones que incluyan sanciones a agentes estatales que incumplen con su deber de actuar con debida diligencia en esta materia, por acción u omisión. Implementen un plan de formación feminista para profesionales de todos los ámbitos que intervienen en estos casos: aparatos de justicia, servicios de salud, policías, instituciones educativas, asociaciones vecinales, medios de comunicación, entre otros. Mejoren y especialicen los sistemas judiciales asegurando la accesibilidad física, económica y cultural de las mujeres a la justicia, incluyendo instrumentos adecuados para la investigación y sanción efectiva de los crímenes, y generación de la información judicial necesaria para su retroalimentación, así como la publicidad de las sentencias para la rendición de cuentas y control desde la sociedad civil. Eliminen procedimientos policiales, administrativos o judiciales que discriminan a las mujeres o las ponen en peligro, incluyendo la conciliación. Asimismo, deben poner en práctica mecanismos y acciones concretas para erradicar los estereotipos de género en los procesos judiciales, etapas de investigación y/o procesamiento de casos (VIII Conferencia sobre Femicidio/Feminicidio, 2015, p. 2).

En síntesis, después de transcurridas casi dos décadas del siglo XXI, los procesos de nombrar con palabras, delimitar con términos y conceptualizar tipos penales han configurado dos tipos penales que aún no son suficientes para velar por los derechos de las mujeres. En medio de las discrepancias procedimentales para su aplicabilidad judicial y con el incremento de las tensiones para administrar justicia, en catorce países de América 
Latina se han tipificado conductas delictivas específicas para sancionar a quienes con sus conductas provoquen la muerte violenta de mujeres; en ocho de ellos se han nombrado como femicidios: Costa Rica, Guatemala, Chile, Nicaragua, Honduras, Panamá, Ecuador y República Bolivariana de Venezuela; en los demás se les denomina feminicidios: El Salvador, México, Perú, Estado Plurinacional de Bolivia, Brasil y Colombia ${ }^{24}$.

\section{DELITO DE FEMICIDIO: ASESINATO DE MUJERES POR RAZONES ASOCIADAS AL GÉNERO}

Diana Russell utilizó el vocablo femicide durante una reunión realizada ante el Primer Tribunal Internacional de Crímenes contra Mujeres, evento que fue instalado por Simone de Beauvoir en 1976. En su ponencia habló sobre la muerte violenta como una forma extrema de violencia contra las mujeres señalando que el término apareció por primera vez en la literatura para nombrar específicamente "el asesinato de una mujer" 25 . Con la denominación femicidio, las muertes violentas de mujeres comenzaron a tener un nombre propio y a ser visibles en los debates jurídico-sociales; así lo hizo Diana Russell ${ }^{26}$ al incorporar el término para referirse a todas las formas sexistas de asesinato. Jane Caputi y Diana Russell, en 1990, consideraron que el femicidio es un asesinato de mujeres realizado por hombres que están motivados por el odio, el desprecio, el placer o un sentido de propiedad de las mujeres.

Jill Radford y Diana Russell elaboraron diversos modos de conceptualizar la realidad vivida por las mujeres del mundo para establecer el sentido crítico de sus análisis. Por un lado, en 1992 definieron al femicidio como un asesinato misógino de mujeres cometido por hombres que puede ser racista, homofóbico o lesbicidio, marital, serial o en masa, incluso cometido fuera de casa por un extraño. Por otro lado, expusieron la forma en que

\footnotetext{
${ }^{24}$ La debida diligencia del Estado implica la formulación consciente de políticas públicas dirigidas a contrarrestar la violencia contra las mujeres, incluida la penalización de la muerte violenta de mujeres. Desde la década de los noventa, se han elaborado leyes específicas. Consecuente con los principios constitucionales nacionales, estos países, junto a Argentina, han firmado y ratificado la Convención de Belem do Pará y han adoptado la conformación de un organismo rector relacionado con la erradicación de las violencias, aunque con niveles jerárquicos variados.

${ }^{25}$ Haciendo referencia a la obra titulada "A Satirical View of London at the Commencement of Nineteenth Century", de John Corry, publicado en 1801.

${ }^{26}$ La autora hizo uso de la palabra femicide en su libro Rape in Marriage (1982), para nombrar la muerte de mujeres por el hecho de ser mujeres. En la obra Femicide in Global Perspective (2001), incluyó casos ocurridos en Estados Unidos, México, Israel, China, Argelia, África del Sur, Canadá y Australia.
} 
las violencias atraviesan e integran las relaciones sociales y son reforzadas por la cultura ${ }^{27}$; esta legitimación de la violencia en contra de las mujeres fue identificada con estudios llevados a cabo en Inglaterra, Estados Unidos e India. La clasificación proporcionada por estas estudiosas abarca el femicidio íntimo cometido por hombres cercanos a las mujeres asesinadas por tener o haber sostenido una relación intima, un vínculo familiar o una situación de convivencia; el femicidio no íntimo cometido por hombres sin una historia de relaciones cercanas a las mujeres cuya integridad ha sido objeto de un ataque sexual previo a la muerte; y femicidio por conexión cometido por hombres que matan a mujeres diferentes de su objetivo femicida por hallarse en la línea de fuego, al intervenir en defensa de la víctima ${ }^{28}$.

Julia Monárrez ha estudiado la situación de Ciudad Juárez para descifrar los móviles y las características de los asesinatos de mujeres jóvenes junto a la impunidad creada y sostenida por el Estado. Con base en sus investigaciones, dice que el femicidio es el asesinato de mujeres por razones asociadas con su género, y agrega que constituye una forma extrema de violencia de género ejercida por hombres que desean obtener mayor poder, mantener la dominación o incrementar el control sobre las mujeres. Su trabajo teórico, que se basa en datos recogidos entre 1993 y 2005, la lleva a proponer el uso del término femicidio. Con este término, diferencia el femicidio de los asesinatos sin motivaciones de género, realiza una agrupación con base en las fuentes analizadas: femicidio familiar (íntimo e infantil), femicidio sexual sistêmico (organizado o desorganizado) y femicidio por ocupaciones estigmatizadas (realizadas por mujeres). La autora observa la ausencia de investigación en los casos de muertes violentas ocurridas en

\footnotetext{
${ }^{27}$ En su libro "Femicidio: la política del asesinato de mujeres".

${ }^{28}$ Siguiendo estos aportes recorridos en la literatura e identificados en la realidad cotidiana, Patsilí Toledo se fija en que el femicidio constituye: un continuum de terror anti-femenino que incluye una amplia variedad de abusos verbales y físicos, tales como: violación, tortura, esclavitud sexual (particularmente por prostitución), abuso sexual infantil incestuoso o extra-familiar, golpizas físicas y emocionales, acoso sexual (por teléfono, en las calles, en la oficina, y en el aula), mutilación genital (clitoridectomías, escisión, infibulaciones), operaciones ginecológicas innecesarias (histerectomías gratuitas), heterosexualidad forzada, esterilización forzada, maternidad forzada (por la criminalización de la contracepción y del aborto), psicocirugía, negación de comida para mujeres en algunas culturas, cirugía plástica, y otras mutilaciones en nombre del embellecimiento. Siempre que estas formas de terrorismo resultan en muerte, ellas se transforman en femicidios" (2009, p. 25).
} 
México, describe los obstáculos que impiden la administración de justicia en la región y denuncia la falta de acciones estatales para reparar los daños causados ${ }^{29}$.

Ana Carcedo se refiere a las muertes violentas o a los asesinatos de mujeres a manos de hombres y otra por usar el concepto de femicidio para diferenciar estos asesinatos de los homicidios de mujeres. Sus intereses investigativos abarcan la situación de impunidad como una expresión de la falta de voluntad política de los Estados para frenar la violencia y esclarecer la muerte violenta de mujeres. Se inclina por ofrecer soluciones políticas para enfrentar a la impunidad ya que, en el ámbito de la justicia penal, llega a limitar el seguimiento del hecho femicida y a eludir las responsabilidades de otros actores. Monserrat Sagot ha investigado las muertes violentas en diez países; reporta que el sector judicial-policial es el itinerario más frecuentemente recorrido por las parientes de las mujeres asesinadas cuando comprenden que las muertes no fueron causadas por ellas y cuando son conscientes de que se trata de un delito específico, situación que tiene que ser mostrada y denunciada ante el sistema judicial.

Ambas activistas se han detenido en las particularidades de los femicidios registrados en Costa Rica, han documentado cómo los estragos provocados por la violencia ejercida por los hombres han traspasado los límites de lo íntimo y de los afectos y han denunciado cómo en la investigación estas conductas delictivas se han dejado fijas en lo personal y en lo privado. También han descrito una amplia variedad de abusos físicos, con sus circunstancias particulares, que habiendo provocado la muerte no encajan en los agravantes descritos en los códigos penales ${ }^{30}$ pero sí reclaman el "cambio de patrones culturales basados en la supremacía masculina y la disponibilidad femenina", tal como lo ha dicho Jennie Dador (2012, p. 20). Incluso, Rocío González ha encontrado que cuando los hechos son cometidos por parejas, ex-parejas u otras personas conocidas "se producen por

\footnotetext{
${ }^{29}$ Dora Munévar señala que "en las comisarías, las estaciones de policía y las dependencias oficiales, las mujeres se encuentran con un sinfín de obstáculos, incluyendo las legislaciones ineficaces que lentifican el proceso y desmotivan el impulso inicial [...]; entre ellos sobresalen la indiferencia de los funcionarios y las funcionarias, el desconocimiento sobre el tema, la burocracia imperante, los procedimientos y papeleos extensos, los prejuicios y los comentarios acusadores cara-a-cara" (2011, p. 87-88).

${ }^{30}$ El homicidio agravado previsto en otros países, como en Argentina, indica que los agravantes de género hacen parte del delito de homicidio. Estos agravantes abarcan circunstancias objetivas o elementos subjetivos para reconfigurar las disposiciones vigentes de homicidio, pero conservando el principio de neutralidad por medio del cual hombres y mujeres son iguales ante la ley.
} 
medios más crueles y dolorosos y generalmente se encuentran enmarcadas por relaciones se subordinación y abuso" (2014, p. 273, nota 8$)$.

En este contexto, recordamos que Costa Rica, Guatemala, Chile, Nicaragua, Honduras, Panamá, Ecuador y la República Bolivariana de Venezuela, han optado por incluir el tipo penal denominado femicidio (tabla 1A, tabla 1B), a través de formas normativas diferenciadas que abarcan desde una Ley de penalización, una Ley Integral contra la violencia, una reforma a la Ley orgánica o una Ley contra el femicidio y otras formas de violencia, hasta la reforma al código penal y a las normas vigentes, la agregación de un artículo y la incorporación de la figura de femicidio, nombrada de manera explícita (tabla 1A). Las descripciones de los delitos establecidos en Guatemala y en Nicaragua contienen una serie de actos violentos y de vivencias adversas que, por haber ocurrido antes de la muerte violenta, han de ser tenidas en cuenta en la investigación criminal. Por consiguiente, resurge el análisis sobre la clase y la frecuencia con que ocurren los actos de violencia previos y sus conexiones con los indicios o antecedentes de violencia para describir los elementos del tipo penal: ellos dan cuenta del menosprecio expresado con respecto a lo femenino y hacia ese cuerpo de mujer.

Cuatro países, Guatemala, Nicaragua, Panamá y Venezuela, han incluido enfoques transversales en la tipificación, estos se caracterizan por usar definiciones amplias orientadas a comprender la violencia contra las mujeres y a traspasar los límites de lo íntimo; los demás países, Costa Rica, Chile, Honduras y Ecuador, se han inclinado por permanecer en el ámbito de lo penal al restringir sus definiciones de violencia contra las mujeres solo a los casos relacionales o afectivos más próximos e íntimos. En Costa Rica y Chile $^{31}$ se ha tipificado el femicidio íntimo indicando que se trata de asesinatos de mujeres realizados por quien es o ha sido esposo o conviviente. En Honduras se destacan el odio y el menosprecio a las mujeres mientras que en Ecuador la discriminación o cualquier otra forma de violencia aparecen como elementos del tipo (tabla 1B).

\footnotetext{
${ }^{31}$ En este país, según Lorena Astudillo, "la información estadística basada en dichos parámetros hace que las estadísticas construidas sean parcializadas y no den cuenta de la realidad del femicidio, dejando fuera el resto de casos de violencia por razón de género. Actualmente no existe un registro nacional único y transversal a todas las instituciones que trabajan en el problema, es así como podemos encontrar estadísticas construidas por el Ministerio de la Mujer, cuyas cifras discrepan de las que encontramos, por ejemplo, en el Ministerio Público" (2017, p. 20).
} 


\section{DELITO DE FEMINICIDIO: GENOCIDIO CONTRA LAS MUJERES, POR SER DEL SEXO FEMENINO, SER CIERTO TIPO DE MUJER Y POR SER MUJER}

A partir del uso de la palabra femicide, en inglés, y aduciendo una traducción menos literal y más política, Marcela Lagarde introdujo en 1994 el concepto de feminicidio para nombrar la muerte violenta de mujeres.

Figura 1 - Ubicación geopolítica

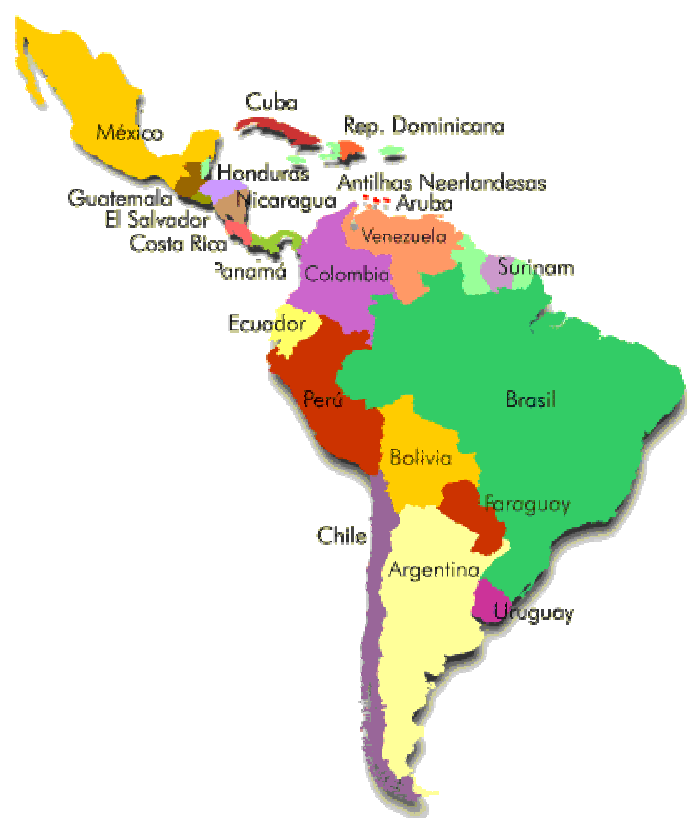

Tabla 1A - Delito de femicidio en ocho países de América Latina

\begin{tabular}{|l|l|l|}
\hline No. & País & Nombre de la norma \\
\hline 1 & Costa Rica & $\begin{array}{l}\text { Art. 21, Ley No. 8.589 de 2007 } \\
\text { Ley de penalización de la violencia contra las mujeres }\end{array}$ \\
\hline 2 & Guatemala & $\begin{array}{l}\text { Decreto 22-2008 } \\
\text { Ley contra el femicidio y otras formas de violencia contra la Mujer }\end{array}$ \\
\hline 3 & Chile & $\begin{array}{l}\text { Ley 20.480 de } 2010 \\
\text { Reforma del Código Penal (artículo 390) } \\
\text { y Ley 20.066 sobre violencia intrafamiliar }\end{array}$ \\
\hline 4 & Nicaragua & $\begin{array}{l}\text { Ley No. 779 de 2012 } \\
\text { Ley Integral contra la violencia hacia las Mujeres y de Reformas a la Ley N641, } \\
\text { Código Penal }\end{array}$ \\
\hline 5 & Honduras & $\begin{array}{l}\text { Decreto 23-2013 } \\
\text { Reforma del Código Penal, agrega el artículo 118a , e incorpora la figura del } \\
\text { femicidio }\end{array}$ \\
\hline 7 & Panamá & $\begin{array}{l}\text { Ley 82 de 2013 } \\
\text { Reforma del Código Penal }\end{array}$ \\
\hline 8 & $\begin{array}{l}\text { República Bolivariana de } \\
\text { Venezuela }\end{array}$ & $\begin{array}{l}\text { Código Orgánico Integral Penal (COIP) de 2014 } \\
\text { Reforma del Código Penal }\end{array}$ \\
\hline
\end{tabular}

Fuente: Cepal (2015); Cepal, 2014, p. 71; Fiscalía General, 2016, p. 13;

https://historiaemaus.wordpress.com/2008/10/27/mapa-america-latina/ 
Tabla 1B - Tipo penal de femicidio según enfoque, elementos del delito y vigencia

\begin{tabular}{|c|c|c|c|c|}
\hline No. & Tipo penal & Enfoque & Elementos del delito & Vigencia \\
\hline 1 & $\begin{array}{l}\text { Femicidio } \\
\text { (íntimo). } \\
\text { Tipo penal } \\
\text { autónomo } \\
\text { Violencia física }\end{array}$ & $\begin{array}{l}\text { Enfoque } \\
\text { penal }\end{array}$ & $\begin{array}{l}\text { En relación de matrimonio o en } \\
\text { unión de hecho }\end{array}$ & $\begin{array}{l}\text { Publicada y vigente a partir del } 30 \\
\text { de mayo de } 2007\end{array}$ \\
\hline 2 & $\begin{array}{l}\text { Femicidio } \\
\text { Tipo penal } \\
\text { autónomo } \\
\text { Delitos y penas }\end{array}$ & $\begin{array}{l}\text { Enfoque } \\
\text { transversal }\end{array}$ & $\begin{array}{l}\text { Contexto de relaciones desiguales } \\
\text { de poder entre hombres y mujeres, } \\
\text { en ejercicio del poder de género en } \\
\text { contra de las mujeres }\end{array}$ & $\begin{array}{l}\text { Publicada el } 7 \text { de mayo de } 2008, \\
\text { vigente } 7 \text { días después de su } \\
\text { publicación ( } 15 \text { de mayo de } 2008 \text { ) }\end{array}$ \\
\hline 3 & $\begin{array}{l}\text { Femicidio } \\
\text { (íntimo). } \\
\text { Reforma: delito } \\
\text { de parricidio en el } \\
\text { Código Penal. } \\
\text { Crímenes y } \\
\text { delitos contra las } \\
\text { personas. }\end{array}$ & $\begin{array}{l}\text { Enfoque } \\
\text { penal }\end{array}$ & $\begin{array}{l}\text { Si es o ha sido la cónyuge o } \\
\text { conviviente }\end{array}$ & $\begin{array}{l}\text { Publicada el } 18 \text { de diciembre de } \\
2010, \text { vigente el día de su } \\
\text { publicación (principio de vigencia } \\
\text { inmediata de la ley) }\end{array}$ \\
\hline 4 & $\begin{array}{l}\text { Femicidio } \\
\text { Tipo penal } \\
\text { autónomo. } \\
\text { Delitos de } \\
\text { violencia contra } \\
\text { las mujeres }\end{array}$ & $\begin{array}{l}\text { Enfoque } \\
\text { transversal }\end{array}$ & $\begin{array}{l}\text { Relaciones desiguales de poder, ya } \\
\text { sea en el ámbito público o privado }\end{array}$ & $\begin{array}{l}\text { Publicada el } 22 \text { de febrero de } 2012 \text {, } \\
\text { vigente } 120 \text { días después de su } \\
\text { publicación (junio de 2012) }\end{array}$ \\
\hline 5 & $\begin{array}{l}\text { Femicidio } \\
\text { Tipo penal } \\
\text { autónomo }\end{array}$ & $\begin{array}{l}\text { Enfoque } \\
\text { penal }\end{array}$ & $\begin{array}{l}\text { Por razones de género con odio y } \\
\text { menosprecio por su condición de } \\
\text { mujer }\end{array}$ & $\begin{array}{l}\text { Publicado el } 6 \text { de abril de } 2013 \text {, en } \\
\text { vigencia } 20 \text { días después de su } \\
\text { publicación }\end{array}$ \\
\hline 6 & $\begin{array}{l}\text { Femicidio } \\
\text { Tipo penal } \\
\text { autónomo }\end{array}$ & $\begin{array}{l}\text { Enfoque } \\
\text { transversal }\end{array}$ & $\begin{array}{l}\text { Por causa de discriminación o } \\
\text { cualquier otra forma de violencia }\end{array}$ & $\begin{array}{l}\text { Esta Ley comenzará a regir a los } \\
\text { dos meses de su promulgación (a } \\
\text { los veintiún días del mes de } \\
\text { octubre del año dos mil trece) }\end{array}$ \\
\hline 7 & $\begin{array}{l}\text { Femicidio } \\
\text { Tipo penal } \\
\text { autónomo }\end{array}$ & $\begin{array}{l}\text { Enfoque } \\
\text { penal }\end{array}$ & $\begin{array}{l}\text { Como resultado de relaciones de } \\
\text { poder en cualquier tipo de } \\
\text { violencia, por el hecho de ser mujer } \\
\text { o por condición de género }\end{array}$ & $\begin{array}{l}\text { Entrará en vigencia en ciento } \\
\text { ochenta días contados a partir de } \\
\text { su publicación en el Registro } \\
\text { Oficial: } 10 \text { de febrero de } 2014\end{array}$ \\
\hline 8 & $\begin{array}{l}\text { Femicidio } \\
\text { Tipo penal } \\
\text { autónomo }\end{array}$ & $\begin{array}{l}\text { Enfoque } \\
\text { transversal }\end{array}$ & $\begin{array}{l}\text { Por odio o desprecio a su condición } \\
\text { de mujer. } \\
\text { En el contexto de relaciones de } \\
\text { dominación y subordinación } \\
\text { basadas en el género }\end{array}$ & $\begin{array}{l}\text { Veinticinco días del mes de } \\
\text { noviembre de dos mil catorce }\end{array}$ \\
\hline
\end{tabular}

Fuente: Cepal (2015); Cepal, 2014, p. 71; Fiscalía General, 2016, p. 13

Con el propósito de desligar la conducta punible del significado dado al homicidio y considerando que la noción de asesinato deja por fuera el influjo de los contextos, elimina el peso de las circunstancias que rodean cada una de las muertes violentas y las condiciones históricas subyacentes en los atentados contra la integridad, la autonomía, la libertad y la vida de todas las mujeres, la autora aboga por el uso del tipo penal feminicidio. 
Con este término de feminicidio, la legisladora mexicana reitera que se trata de un crimen de Estado derivado de la ausencia de programas que garanticen la libertad y la vida a las mujeres; abarca la falta de acciones centradas en la prevención real, la atención a los deseos de justicia por parte de las mujeres que han vivido de manera reiterada situaciones de violencia de género, y la negligencia institucional para investigar cada caso e imponer penas de acuerdo con la gravedad de los hechos y sus circunstancias relacionadas con el género. Además, otras autoras retoman los nexos del feminicidio con el móvil o la intención homicida y, sobre todo, en el sentir de Olga Amparo Sánchez, esta denominación "permite subrayar el carácter político y social de las violencias en contra de las mujeres e interpretar dichos crímenes en contextos de relaciones de opresión y subordinación entre varones y mujeres en el ámbito público y en el privado, y determinar la responsabilidad del Estado" (2010, p. 23).

Catharine MacKinnon, como teórica política y defensora que actúa en procesos legales internacionales, presentó cargos por prácticas genocidas y feminicidas de manera separada para exigir una tipificación específica porque el feminicidio es un crimen distinto; ha discutido el peso que tienen la fuerza y la coerción sobre la autonomía y la autodeterminación de las mujeres en situaciones de guerra y por razones de género, por su pertenencia a un determinado grupo étnico o porque son percibidas como traidoras; $y$ devela el odio arraigado en racismos, prejuicios de clase y actos de xenofobia, tal como queda materializado en la violación y en el asesinato masivo de mujeres. Rita Segato también sostiene que el concepto de feminicidio es el indicado para referirse a las muertes de mujeres en las que aparecen las motivaciones misóginas interpersonales; con base en sus investigaciones afirma que la muerte violenta de una mujer constituye un feminicidio que se produce por el hecho de ser mujer o por tener cuerpo de mujer. Como son actos ejecutados por hombres, los feminicidas atacan cuerpos sexuados, construidos a lo largo de la historia con sustratos ideológicos, derivados de la diferencia sexual y arraigados en unas representaciones sociales subalternas e inferiores.

Las autoras que han optado por el uso del término feminicidio para referirse al homicidio de una mujer por razones de género, consideran que es una alternativa que obliga a las partes involucradas en la investigación penal a analizar el contexto en el que 
sucedió la conducta punible. La conjugación entre hechos y circunstancias de género, junto a los antecedentes misóginos del agente, permiten comprender la dinámica de la violación de los derechos humanos de las mujeres, principalmente el derecho a vivir sin violencias, sobre todo porque "en algunos trabajos [...] se abordan los aspectos legales del feminicidio, su tipificación, su conexión con los derechos humanos y el estado de la legislación para el caso de países concretos" (BOIRA et al., 2015, p. 34).

En este sentido, el feminicidio ha quedado en las estipulaciones penales adoptadas en El Salvador, México, Perú, Estado Plurinacional de Bolivia, Brasil y Colombia (tabla 2A, tabla 2B), dando origen a los sistemas de información y registro de un tipo penal "pluriofensivo que busca proteger diversos bienes jurídicos, a saber: la vida, la integridad personal, la dignidad humana, la igualdad, la no discriminación y el libre desarrollo de la personalidad" (Sentencia C-297/16: 14). Sin embargo, las observaciones posteriores a la implementación de estos cambios en el régimen penal señalan que el mayor déficit para la investigación se deriva precisamente de la ausencia de información fidedigna.

Tabla 2A - Delito de feminicidio en seis países de América Latina

\begin{tabular}{|l|l|l|}
\hline No. & País & Nombre de la norma \\
\hline 9 & El Salvador & $\begin{array}{l}\text { Decreto } 520 \text { de } 2010 \\
\text { Ley Especial Integral para una Vida Libre de Violencia para las Mujeres }\end{array}$ \\
\hline 10 & $\begin{array}{l}\text { México } \\
\text { Reforma del Código } \\
\text { Penal Federal } \\
\text { (artículo 325) }\end{array}$ & $\begin{array}{l}\text { Decreto de } 2012 \text { por el que se reforman y adicionan diversas disposiciones del } \\
\text { Código Penal Federal, de la Ley General de Acceso de las Mujeres a una Vida Libre } \\
\text { de Violencia, de la Ley Orgánica de Administración Pública Federal, de la Ley } \\
\text { Orgánica de la Procuraduría General de la República }\end{array}$ \\
\hline 11 & Perú & $\begin{array}{l}\text { Ley 30.068 de 2013 } \\
\text { Modificación de la Ley de Feminicidio de 2011 y reforma del Código Penal (artículo } \\
107 \text { y 108-B). } \\
\text { Ley que modifica el artículo 107o del Código Penal incorporando el delito de } \\
\text { Feminicidio (Ley No 29819). Ley que incorpora el artículo 108o-A al Código Penal y } \\
\text { modifica los artículos 1070, 46-B y 46-C del Código Penal y el artículo 46 del Código } \\
\text { de Ejecución Penal, con la finalidad de prevenir, sancionar y erradicar el } \\
\text { Feminicidio (Ley № 30068). }\end{array}$ \\
\hline 12 & $\begin{array}{l}\text { Estado } \\
\text { Plurinacional de } \\
\text { Bolivia }\end{array}$ & $\begin{array}{l}\text { Ley No. 348 del 9 de marzo de 2013 } \\
\text { Ley Integral para garantizar a las mujeres una vida libre de violencia }\end{array}$ \\
\hline 13 & Brasil & $\begin{array}{l}\text { Ley 13.104 del 9 de marzo de 2015 } \\
\text { Ley del feminicidio, que transformó en crimen el asesinato por motivos de género. } \\
\text { Modifica el artículo 121 del código penal y el artículo 1 de la ley 8072 de 1990 }\end{array}$ \\
\hline
\end{tabular}

\footnotetext{
${ }^{32}$ Fue reformado el Código Penal para reconocer la imprescriptibilidad de la acción penal en los delitos de tortura y delitos cometidos contra

la libertad sexual de menor o incapaz: Decreto Legislativo Número 217 (10-12-2015), Diario Oficial Número 237, tomo 409 (23-12-2015).
} 


\begin{tabular}{|l|l|l|}
\hline 14 & Colombia & $\begin{array}{l}\text { Ley Rosa Elvira Cely o Ley } 1761 \text { de 2015, por la cual se crea el tipo penal de } \\
\text { feminicidio como delito autónomo. Arts. 104A y 104B, tipo penal y circunstancias } \\
\text { de agravación }\end{array}$ \\
\hline
\end{tabular}

Fuente: Cepal (2015); Cepal, 2014, p. 71; Carla Elizabeth Escobar Cubias, Rebeca Saraí González Maravilla y livania Beatriz Navarro N. (2014, p. 125-130); Fiscalía General, 2016, p. 13;

https://historiaemaus.wordpress.com/2008/10/27/mapa-america-latina/

Tabla 2B - Tipo penal de feminicidio según enfoque, elementos del delito y vigencia

\begin{tabular}{|c|c|c|c|c|}
\hline No. & Enfoque & Tipo penal adoptado & Elementos del delito & Vigencia \\
\hline 9 & $\begin{array}{l}\text { Enfoque } \\
\text { transversal }\end{array}$ & $\begin{array}{l}\text { Feminicidio. } \\
\text { Tipo penal autónomo. } \\
\text { Delitos y sanciones }\end{array}$ & $\begin{array}{l}\text { Motivos de odio o } \\
\text { menosprecio por su } \\
\text { condición de mujer }\end{array}$ & $\begin{array}{l}\text { Vigente a partir del } 1 \text { de enero } \\
\text { de } 2012\end{array}$ \\
\hline 10 & $\begin{array}{l}\text { Enfoque } \\
\text { transversal }\end{array}$ & $\begin{array}{l}\text { Feminicidio. } \\
\text { Tipo penal autónomo. } \\
\text { Delitos contra la vida y } \\
\text { la integridad corporal }\end{array}$ & Por razones de género & $\begin{array}{l}\text { Reforma de fecha } 13 \text { de junio } \\
\text { de } 2012 \text {, vigente a partir del } 15 \\
\text { de junio de } 2012\end{array}$ \\
\hline 11 & Enfoque penal & $\begin{array}{l}\text { Feminicidio. } \\
\text { Reforma: delito de } \\
\text { parricidio en el Código } \\
\text { Penal. } \\
\text { Delitos contra la vida, } \\
\text { el cuerpo y la salud }\end{array}$ & $\begin{array}{l}\text { Matar a una mujer por } \\
\text { su condición de tal; } \\
\text { amplía el feminicidio } \\
\text { restringido a pareja o ex- } \\
\text { pareja }\end{array}$ & $\begin{array}{l}\text { Ley № } 29819 \text {, publicada el } 27 \\
\text { de diciembre de } 2012 \text {. } \\
\text { Ley № } 30068 \text {, publicada el } 18 \\
\text { de julio de } 2013 \text {, vigente desde } \\
\text { el día siguiente de su } \\
\text { publicación. }\end{array}$ \\
\hline 12 & $\begin{array}{l}\text { Enfoque } \\
\text { transversal }\end{array}$ & $\begin{array}{l}\text { Feminicidio. } \\
\text { Tipo penal autónomo }\end{array}$ & $\begin{array}{l}\text { Ampliado en nueve } \\
\text { Circunstancias }\end{array}$ & $\begin{array}{l}\text { Vigente desde el día de su } \\
\text { publicación }\end{array}$ \\
\hline 13 & $\begin{array}{l}\text { Enfoque } \\
\text { transversal }\end{array}$ & $\begin{array}{l}\text { Feminicidio. } \\
\text { Tipo penal autónomo }\end{array}$ & $\begin{array}{l}\text { Por violencia domestica } \\
\text { y familiar; por } \\
\text { menosprecio o } \\
\text { discriminación } \\
\text { relacionada con la } \\
\text { condición de mujer }\end{array}$ & $\begin{array}{l}\text { Entra en vigor en la fecha de su } \\
\text { publicación, el } 9 \text { de marzo de } \\
2015\end{array}$ \\
\hline 14 & $\begin{array}{l}\text { Enfoque } \\
\text { transversal }\end{array}$ & $\begin{array}{l}\text { Feminicidio. } \\
\text { Tipo penal autónomo }\end{array}$ & $\begin{array}{l}\text { Motivos de género y } \\
\text { discriminación. Por su } \\
\text { condición de ser mujer o } \\
\text { por motivos de su } \\
\text { identidad de género }\end{array}$ & $\begin{array}{l}\text { Promulgada el } 6 \text { de julio de } \\
2015 ; \text { rige a partir de esta fecha } \\
\text { y deroga el numeral undécimo } \\
\text { del artículo } 104 \text { del Código } \\
\text { Penal - Ley } 599 \text { de } 2000, \text { y } \\
\text { demás disposiciones que le } \\
\text { sean contrarias }\end{array}$ \\
\hline
\end{tabular}

Fuente: Cepal (2015); Cepal, 2014, p. 71; Carla Elizabeth Escobar Cubias, Rebeca Saraí González Maravilla y livania Beatriz Navarro N. (2014, p. 125-130); Fiscalía General, 2016, p. 13

Los tipos penales adoptados en Bolivia, El Salvador y México hacen parte de una ley especial, una ley general o una ley integral; mientras que en Perú, Brasil y Colombia se dispone de una ley de feminicidio (tabla 2A). Los enfoques transversales que abarcan definiciones amplias de la muerte violenta de mujeres han sido incorporados en cinco países, mientras que el enfoque penal, que hace énfasis en los asuntos de técnica jurídica y solo involucra los casos íntimos, ha sido adoptado en Perú (tabla 2B). 
En ambas situaciones, además de establecer los alcances del tipo penal autónomo, se puede sopesar la debida diligencia estatal, y su exigibilidad como derecho de las mujeres; incluso es posible comprender las repercusiones de la legislación penal cuando se analizan las razones por las cuales "tipificaron el feminicidio como delito autónomo e incluyeron criterios de violencia anterior al asesinato como un elemento para establecer la intención" (Sentencia C-297/16, p. 55). La documentación de dicha intención pasa por los sistemas de información y registro, seguimiento y atención, denuncia e investigación de las violencias en todas sus manifestaciones.

En Bolivia, se ha organizado el Sistema de Información para la Vigilancia Ciudadana desde una Perspectiva de Género (Sivige). Se trata de una herramienta, de acuerdo con Jennie Dador y Jeannette Llaja, que registra "informes panorámicos de la violencia intrafamiliar, recoge y sistematiza los datos registrados en las Brigadas de Protección a la Familia, por los Servicios Legales Integrales Municipales, las Organizaciones no Gubernamentales y los Juzgados de Instrucción de Familia" (2008, p. 47).

En El Salvador, se ha creado el Sistema Nacional de Datos, Estadísticas e Información de Violencia contra las Mujeres ${ }^{33}$ que busca hacer seguimiento a las políticas establecidas para erradicar las violencias. Según Morena Herrera, se está desarrollando "una herramienta de gestión de la información sobre los hechos, las mujeres que enfrentan violencia y las personas agresoras, así como, sobre los efectos causados por dicha violencia" (2017, p. 7).

En México, se hace énfasis en la información sobre las mujeres asesinadas por razones de género. Para ello, desde 2007, se tiene como marco legal la Ley General de Acceso de las Mujeres a una Vida Libre de Violencia (LGAMVLV); según Lucía Lagunes, esta ley propone desarrollar "un Banco Nacional de datos e Información sobre Casos de violencia contra las Mujeres (BANAVIM), incluyendo los tipos y modalidades de violencia contra la mujer" (2017, p. 22).

\footnotetext{
${ }^{33}$ Una dependencia a cargo del Ministerio de Justicia y Seguridad Pública y de la Dirección de Estadísticas y Censos (DIGESTIC).
} 
En Perú, se cuenta con dos sistemas de registro destinados a captar los hechos de feminicidio, un programa y un observatorio. Por un lado, el Programa Nacional contra la Violencia Familiar y Sexual del Ministerio de la Mujer y Poblaciones Vulnerables (MIMP) que, según Liz Meléndez "inicia el Registro de víctimas de feminicidio y tentativas, a cargo del Programa Nacional contra la Violencia familiar y Sexual" (2017, p. 10). De otro lado, el Observatorio de la Criminalidad del Ministerio Público que busca documentar las muertes violentas de mujeres, también las tentativas, como feminicidio íntimo, feminicidio no íntimo o feminicidio por conexión ${ }^{34}$.

En Brasil, se requiere el seguimiento de los procesos judiciales iniciados por feminicidio. Carla Gisele Batista, manifiesta que existe una seria "falta información oficial sobre las muertas, hay problemas en las estadísticas y deficiencias en los datos de la policía y la justicia" (2017, p. 18). Las estadísticas se producen sin tener en cuenta datos sobre "el sexo y el color/raza de la víctima".

En Colombia, existe un Sistema Nacional de Estadísticas sobre Violencia Basada en Género. Este sistema es coordinado entre el Departamento Nacional de Estadísticas, el Ministerio de Justicia y del Derecho y el Instituto de Medicina Legal y Ciencias Forenses. Según Ana María Sánchez y F. León, se trata de una alternativa que busca traspasar el mero "conteo de mujeres asesinadas, todo ello alrededor del derecho penal, [dado que se trata de] un instrumento que dé cuenta de contextos socioculturales, con miras a eliminar la discriminación que permea a todo el derecho y la sociedad" (2015, p. 308).

\section{CAMINOS COMUNES PARA PENSAR}

Los debates impulsados por mujeres y hombres conscientes de las desigualdades producidas y reproducidas desde y a través del campo del derecho y la investigación penal, han desatado mudanzas en torno a la defensa de los derechos de las ciudadanas a través de la vía punitiva. Si bien en los 14 países latinoamericanos que han optado por implantar

\footnotetext{
${ }^{34}$ De acuerdo con Liz Meléndez, "el Observatorio de la Criminalidad, tiene bajo su responsabilidad el Registro de Feminicidio y Tentativa de feminicidio en virtud de la Resolución de la Fiscalía de la Nación № 216-2009-MP-FN. Luego, mediante Resolución de la Fiscalía de la Nación № 1690-2009-MP-FN, se aprueba la Directiva № 006-2009-MPFN, que establece ampliar el Registro de Feminicidio a los casos en los cuales el agresor no tenía una relación de pareja o familiar con la víctima (feminicidio no íntimo) así como los casos de tentativa de feminicidio" (2017, p. 10, nota 13$)$.
} 
el delito de femicidio o el delito de feminicidio se han descrito diferentes condiciones estructurales para configurar el hecho punible, estos tipos establecen asociaciones entre lo femenino y lo débil e inferior pero mediado por la misoginia u odio hacia lo que representa ser mujer, una explicación apoyada por Rita Segato "como consecuencia de la infracción femenina a las dos leyes del patriarcado: la norma del control o posesión sobre el cuerpo femenino y la norma de la superioridad masculina" (2006, p. 4).

La descripción de cada tipo penal hace énfasis en que existe una cercanía entre los hombres atacantes y las mujeres atacadas, ya se trate de parejas o de ex-parejas, y en que los contextos cotidianos donde han vivido muchas mujeres atacadas han estado presentes física, sicológica y simbólicamente los odios, los menosprecios, los sesgos y los estereotipos de género, las violaciones sexuales o los ensañamientos. Estos han dejado huellas en los cuerpos de las mujeres desde mucho antes de haber terminado inertes en sus casas, sus lugares de trabajo, en el vecindario o en cualquier espacio de la región donde vivían; se trata de una cadena de actos que reclaman labores de investigación basadas en "elementos de prueba que permitan establecer no solo la ocurrencia de los hechos y la participación del imputado en ellos, sino que además tender a establecer el contexto relacional en el que estos ocurren" (CAR SILVA, 2013, p. 179).

Mediante el activismo legal de las mujeres comprometidas con el estudio de las alternativas penales se siguen denunciando los cimientos estructurales de las violencias contra las mujeres para erradicarlas desde sus basamentos. A la vez, estos mismos discursos, con sus acciones comprometidas, están intensificando las resistencias de quienes históricamente han quedado fuera de la titularidad y del ejercicio de sus derechos, a sabiendas de que el derecho penal no es la mejor opción para construir los cambios estructurales indispensables en cada país, pero sí para impulsar el proceso de juzgamiento y sanción de quienes han incurrido en la realización de cada tipo penal adoptado como autores de las muertes violentas de las mujeres. 


\section{REFERENCIAS}

ASTUDILLO, Lorena. Por una definición más amplia del feminicidio (pp. 20-21). In: Jiménez, Patricia y Martínez Fernández, Ana (eds.). Feminicidio: un fenómeno global De Bruselas a San Salvador. Heinrich-Böll-Stiftung - Unión Europea. Bruselas, 2017.

BATISTA, Carla Gisele. Una ley insuficiente y la pérdida de perspectiva integral (pp. 18-19). In: Jiménez, Patricia y Martínez Fernández, Ana (eds.). Feminicidio: un fenómeno global De Bruselas a San Salvador. Heinrich-Böll-Stiftung - Unión Europea. Bruselas, 2017.

BENAVIDES, F.S.. Feminicidio y derecho penal. Revista Criminalidad, v. 57, n. 1, p. 75-90, 2015.

BOIRA, S.; MARCUELLO-SERVÓS, Ch.; OTERO, Laura; SANZ BARBERO, Belén y VIVES-CASES, Carmen. Femicidio y feminicidio: un análisis de las aportaciones en clave iberoamericana. Comunitaria, n. 10, p. 27-46, 2015.

CAPUTI, Jane; RUSSELL, Diana. Femicide: speaking the unspeakable. The World of Women, v. 1 , n. 2, p. 34-37, 1990.

CARCEDO, Ana (coord.). No olvidamos ni aceptamos: femicidio en Centroamérica 20002006. Cefemina y Horizons. San José de Costa Rica, 2010.

CARCEDO, Ana; SAGOT, Monserrat. Femicidio en Costa Rica 1990-1999. Instituto Nacional de las Mujeres, Colección Teórica № 1, San José de Costa Rica, 2002.

CAR SILVA, M.. Comentario a la sentencia definitiva condenatoria dictada por el sexto tribunal oral en lo penal de Santiago por el delito de femicidio frustrado y otros. Revista Jurídica del Ministerio Público, n. LV, p. 179-193, 2013.

CEPAL. Comisión Económica para América Latina y el Caribe. El femicidio o feminicidio como tipo específico de delito en las legislaciones nacionales de América Latina: un proceso en curso. Observatorio de igualdad de género de América Latina y el Caribe. Nota para la Igualdad N¹7, Julio, 2015.

CEPAL. Comisión Económica para América Latina y el Caribe. Informe anual 2013-2014. El enfrentamiento de la violencia contra las mujeres en América Latina y el Caribe (LC/G.2626), Santiago de Chile, 2014.

CORN, E.. Un nuevo tipo penal de femicidio en un nuevo Código Penal para Chile. Revista de Derecho, v. XXVIII, n. 1, p. 193-216, 2015.

Corporación Humanas. Estudio exploratorio del feminicio en Cartagena y Medellín. Ediciones Antropos. Bogotá, 2015.

DADOR, Jennie. Historia de un debate inacabado. La penalización del feminicidio en el Perú. Movimiento Manuela Ramo. Lima, 2012.

DADOR, Jennie; LLAJA, Jeannette (Sistematización). Monitoreo sobre feminicidio/femicidio en Bolivia, Ecuador, Paraguay, Perú y República Dominicana. Comité de América Latina y el Caribe para la Defensa de los Derechos de la Mujer CLADEM-. Lima, 2008. 
ESCOBAR CUBIAS, Carla Elizabeth; GONZÁLEZ MARAVILLA; Rebeca Saraí; NAVARRO N., Ilvania Beatriz. Análisis de los elementos del tipo que configuran el feminicidio y su distinción con el homicidio agravado. Trabajo de grado. Universidad de El Salvador, 2014.

FISCALÍA GENERAL DEL ESTADO. Femicidio. Análisis penológico 20 4-2015. Dirección Nacional de Política Criminal. Quito, 2016.

GONZÁLEZ, D.. El delito de parricidio: consideraciones críticas sobre sus últimas reformas.

Política criminal, v. 10, n. 19, p. 2015. [http://www.politicacriminal.cl/Vol_10/n_19/Vol10N19A7.pdf]

GONZÁLEZ, Elvia María. Sobre la experiencia hermenéutica o acerca de otra posibilidad para la construcción del conocimiento. Discusiones Filosóficas, v. 12, n. 18, p. 125-143, 2011.

GONZÁLEZ, Rocío. Cuando el derecho penal no basta. Reflexiones en torno a la tipificación del feminicidio en México. Alegatos, n. 87, p. 271-308, 2014.

HERRERA, Morena. Atrapadas: violência sexual, feminicidio, suicídio feminicida y movilizaciones feministas. In: Jiménez, Patricia y Martínez Fernández, Ana (eds.). Feminicidio: un fenómeno global De Bruselas a San Salvador. Heinrich-Böll-Stiftung Unión Europea. Bruselas, p. 7-9, 2017.

LAGARDE, Marcela. Feminicidio, delito contra la humanidad (en Feminicidio, justicia y derecho, 2005). In: Alejandra de Santiago; Edith Caballero; Gabriela González (edts.). Mujeres intelectuales: feminismos y liberación en América Latina y el CLACSO. Buenos Aires, p. 357-370, 2017.

LAGARDE, Marcela (2008). Antropología, feminismo y política: violencia feminicida y derechos humanos de las mujeres. In: Margaret Bullen; Carmen Díez (coords.). Retos teóricos y nuevas prácticas, Ankulegi Antropologia Elkartea. San Sebastián, p. 211-233, 2008.

LAGUNES, Lucía (2017). La impunidad y la criminalización de la legítima defens. In: Patricia Jiménez; Ana Martínez Fernández (eds.). Feminicidio: un fenómeno global De Bruselas a San Salvador. Heinrich-Böll-Stiftung - Unión Europea. Bruselas, p. 22-23, 2017.

LINDIG, Érika. Discurso y violencia. Elementos para pensar el feminicidio (en Feminicidio: actas de denuncia y controversia, 2010). In: Alejandra de Santiago; Edith Caballero; Gabriela González (edts.). Mujeres intelectuales: feminismos y liberación en América Latina y el CLACSO. Buenos Aires, p. 347-356, 2017.

MAIER, Sabine. ¿La mató sólo por el hecho de ser mujer? Hacia una apropiación interseccional del concepto de feminicidio en el contexto de matrimonios bi-nacionales en Alemania. In: M. Góngora-Mera; S. Costa; G. Gonçalves (eds.). Derecho en América Latina: ¿corrector o (re)productor de desigualdades? desiguALdades.net Working Paper Series, N. 81, p. 60-90, 2015.

MACKINNON, Catherine (2006). Defining rape internationally: a comment on

Akayesu. Columbia Journal of Transnational Law, No. 44: 940-958, 2006. 
MELÉNDEZ, Liz (2017). El feminicidio: entre los datos y la indignación social. In: Patricia Jiménez; Ana Martínez Fernández (eds.). Feminicidio: un fenómeno global De Bruselas a San Salvador. Heinrich-Böll-Stiftung - Unión Europea. Bruselas, p. 10-12, 2017.

MONÁRREZ, Julia. Trama de una injusticia. Feminicidio sexual sistémico en Ciudad Juárez. El Colegio de la Frontera Norte/Porrúa. México, 2009.

MONÁRREZ, Julia. El inventario del feminicidio juarense. Mujer Salud, n. 4, p. 30-43, 2008. MONÁRREZ, Julia. Feminicidio sexual serial en Ciudad Juárez: 1993-2001. Debate Feminista, v. 13, n. 25, p. 2-3, 2002.

MUNÉVAR M., Dora Inés. Delito de femicidio. Muerte violenta de mujeres por razones de género. Estudios socio-jurídicos, v. 14, n. 1, p. 135-175, 2012.

MUNÉVAR M., Dora Inés. Violencias hacia mujeres, niñas y niños (pp. 17 y ss.). In: Dora Inés Munévar M. (ed.). De las violencias que encierran... a las acciones que sanan, I.D.H., Estudios sobre desarrollo humano, (dis)capacidades, diversidades, Facultad de Medicina, Universidad Nacional de Colombia. Bogotá, 2011.

PERAMATO, Teresa. El femicidio y el feminicidio. Revista de Jurisprudencia, No. 1, 2012.

RADFORD, Jill; RUSSELL, Diana (eds.). Feminicidio: la política del asesinato de las mujeres. Universidad Nacional Autónoma de México, México, 2006.

RAMOS, Adriana. Feminicidio: un análisis criminológico-jurídico de la violencia contra las mujeres. Tesis de doctorado. Universidad Autónoma de Barcelona. Barcelona, 2015.

REYES, María Elena (coord.). Los nuevos retos frente al feminicidio. Análisis de expedientes judiciales. Movimiento Manuela Ramos. Lima, 2014.

SALCEDO, Diana María (2017). Desafíos para la documentación y judicialización de los feminicidios en Colombia. In: Patricia Jiménez; Ana Martínez Fernández (eds.). Feminicidio: un fenómeno global De Bruselas a San Salvador. Heinrich-Böll-Stiftung - Unión Europea. Bruselas, p. 13-15, 2017.

SAGOT, Monserrat. Estrategias para enfrentar la violencia contra las mujeres: reflexiones feministas desde América Latina. Athenea Digital, no. 14, p. 215-228, 2008.

SAGOT, Montserrat. Proceso de investigación de la ruta crítica de las mujeres afectadas por la violencia intrafamiliar en América Latina (estudios de caso de diez países), Organización Panamericana de la Salud, Programa Mujer, Salud y Desarrollo. Washington, 2000.

SÁNCHEZ, Ana María; LEÓN, F.. Sentencia del 4 de marzo de 2015: primer pronunciamiento de la Corte Suprema de Justicia en torno al feminicidio. Universitas Estudiantes, n. 12, p. 293-309, 2015.

SÁNCHEZ, Olga Amparo. ¿Será que a las mujeres nos matan porque nos aman? Feminicidios en Colombia 2002 - 2009. Asociación Santa Rita para la Educación y Promoción - FUNSAREP. Corporación Casa de la Mujer. Corporación Vamos Mujer. Ruta Pacífica de las Mujeres. Bogotá, 2010. 
SEGATO, Rita. Que es un feminicidio. Notas para un Debate Emergente. Revista Mora, $\mathrm{n}$. 12, p. 2-13, 2006.

Sentencia C-297/16. Corte Constitucional Colombiana. Magistrada Ponente Gloria Stella Ortiz Delgado. Demanda de inconstitucionalidad contra el literal e) del artículo 20 (parcial) de la Ley 1761 de 2015. Bogotá, D.C., ocho (8) de junio de dos mil dieciséis (2016). TOLEDO, Patsilí. Feminicidio. Oficina del Alto Comisionado para los Derechos Humanos de las Naciones Unidas. México. Recuperado de: http://www.hchr.org.mx/images/doc pub/feminicidio.pdf, 2009.

TUESTA, D.; MUJICA, J.. Problemas en la investigación procesal-penal del feminicidio en el Perú. URVIO, Revista Latinoamericana de Estudios de Seguridad, n. 17, p. 80-95, 2015.

Vergel, J.; Díaz, Diana y Martínez, O.. Relación entre el overkill por arma blanca y el femicidio íntimo. Revista Colombiana de Medicina Legal y Ciencias Forenses, v. 1, n. 1, p. 19-24, 2013.

VIII CONFERENCIA SOBRE FEMINICIDIO / Femicidio. El deber de debida diligencia para erradicar el feminicidio / femicidio. Dos años de diálogo bi-regional sobre género UE CELAC: ¿Cuáles son los avances? 1 de junio 2015, $15 \mathrm{~h} 00$ - $18 \mathrm{~h} 30$ en el Parlamento Europeo. Reunión de seguimiento y estrategia. 2 de junio 2015, 9h00 - 13 h00 en la Plataforma Social Europea, Square de Meeûs 18, 1050. Bruselas, 2015. 